\title{
MODERNIZAÇÃO ARMAMENTISTA NA AMÉRICA DO SUL: PRESSÕES EMPÍRICAS E TEÓRICAS SOBRE AS VISÕES DUALISTAS DE SEGURANÇA REGIONAL
}

\author{
Rafael Duarte Villa ${ }^{1}$
}

\section{Introdução}

Quase toda a produção teórica, que de alguma maneira, tem se ocupado do sistema de segurança sul-americano é unânime em observar dois aspectos: primeiro, a escassa existência de conflitos bélicos entre os seus Estados (a última grande guerra na América do Sul foi a Guerra do Chaco entre Bolívia e Paraguai), A redemocratização iniciada nos 8os, é tida como a variável chave para explicar a transformação das relações países da região em algo próximo de uma comunidade de segurança (Hurrel i998 ou de "longa paz" (Kacowicz 2005); O segundo aspecto é o surgimento de dois subsistemas de segurança diferenciados; de um lado, aquele dos países andinos, com seus problemas de droga, a existência de grupos armados não estatais, existência de conflitos armados intra-estatais, no caso de Colômbia e o Peru querelas territoriais não resolvidas e a existência de Estados com comportamentos militares tradicionais. De outro lado, um subsistema no Cone Sul, que não raramente a bibliografia identifica com uma comunidade de segurança² .

Essa indiferenciação de subsistemas de segurança tem contribuído bastante para alimentar o argumento sobre uma visão dual do subsistema

\footnotetext{
I Professor associado de Relações Internacionais da Universidade de São Paulo (USP). Doutor em ciência política pela USP e pós-doutor pela Columbia University. E-mail: rafaelvi@usp.br 2 Karl Deutsch definiu a comunidade de segurança (pluralista) como "uma região transnacional em que suas sociedades têm expectativas de que conflitos entre os Estados não serão resolvidos por meios de força" em função de que tais Estados formam uma comunidade de segurança (Deutsch I957).
} 
sul-americano, que até perspectivas com influências da teoria crítica, como as de Ruth Diamint, tem observado, ao destacar as relações entre civis, militares e segurança em Sul-américa “(...) as relações entre civis e militares se reconvertem a duas velocidades diferentes: no Cone Sul, embora as diversas dificuldades, há uma recomposição hegemônica, enquanto que nos países andinos, há uma profunda crises das instituições estatais" (Diamint 200I, 24).

Este artigo tenciona essas teses ao mostrar: primeiro, que desenvolvimentos contemporâneos, e preocupações, com a compra de armamento sofisticados, por parte de alguns países sul-americanos, especialmente o Chile a Venezuela e o Brasil nas duas primeiras décadas deste século, é um ponto crítico que tenciona a ideia de uma zona permanente de paz (democrática) na América do Sul. Os momentos críticos sul-americanos não são as guerras, pela ausência das mesmas, mas os momentos em que um build-up armamentista é operado. Em segundo lugar, o build-up armamentista questionam a rigidez visão dual de dois subsistemas de segurança. Na verdade compras de armamentos transformam a região num único complexo regional de segurança posto que aquele não é operado unicamente nem no sistema andino nem no Cone Sul, porém por países de ambas sub-regiões.

Metodologicamente, o estudo dos investimentos militares agregados dos países da região, no início do milênio, são tomados como base empírica para tentar mostrar as tensões de teses fundadas tanto em perspectivas de comunidade de segurança, análises dualistas e, e para mostrar como operam as novas metas político militares de países como Brasil, Chile e a Venezuela, levando em conta tendências de médio prazo que começaram a consolidar-se no período 2003-2007, época em que a região sul-americana passou por uma vigorosa expansão econômica. $\mathrm{O}$ artigo se divide em quatro partes: na primeira se apresentam o que denomino de teses dualistas; na segunda parte, se apresentam desenvolvimentos empíricos do build-up armamentista sul-americano, discutindo especialmente os casos das compras de armamentos no Brasil, Chile e a Venezuela, especialmente no período 2003-2007, em que se dão os principais contratos de compras por países sul-americanos de material armamentista. Na terceira se faz, à luz dos dados empíricos e discussões teóricas, um questionamento das teses duais, e finalmente na conclusão se faz um balanço das tensões nas teses duais sobre o build-up armamentista sul-americano. 


\section{As Teses Dualistas sobre os Sistemas Regionais de Segurança em Sul-américa}

Diversas teorias das relações internacionais, sejam elas de inspiração realistas, institucionalistas e construtivistas coincidem que América Latina tem desembocado num processo histórico de limitados, ou quase nenhum, conflito militar. Numa perspectiva realista clássica os dilemas de segurança têm estado ausentes das relações interestatais regionais. Essa ausência tem sido favorecida pelas longos períodos em que as guerras entre Estados desaparecem da história militar da região e, sobretudo, pela forte convicção da classe política de que seus vizinhos não são ameaças à existência de seus Estados, ou que não modernizam suas capacidades militares com objetivos ofensivos. Como tem apontado Pion-Berlim e Trinkunas, "Civilians not belief that their neighbors are a threats because the history has shown their neighbors rarely attack, so they pay a little attention to defense policy and avoid funding strongly militaries" (Pion-Berlin e Trinkunas 2007, 70). Some-se a isso o fato de que apesar de existir pendências territoriais ${ }^{3}$ estas não parecem suficientemente intensas na América do Sul para gerar uma dinâmica inter-estatal de segurança que gerem percepções de ameaças existenciais, por exemplo surgimento de um estado expansionista. Não há, na história sul-americana, experiências similares das europeias quanto a emergência de Estados expansionistas.

Uma variada produção bibliográfica tem adiantado análises de segurança sobre América do Sul baseadas na dicotomia região andina (complexo tradicional de segurança baseada em políticas de poder) versus Cone Sul como uma comunidade de segurança, Na linha dessa análise, Hirst, ao comentar a fragmentação da agenda de segurança na América Latina tem sublinhado a mesma visão dual do complexo sul-americano quando chama a atenção para o fato da existência em Sul-américa de uma (...) sub-região andina debilitada pela fragilidade de suas instituições estatais e com poucos meios para conter o empurre do narcotráfico e dos grupos armados; e uma área pacífica no Cone Sul comprometida com a integração regional e a mútua confiança sub-regional, particularmente nos casos de Argentina e Brasil” (Hirst 2006, 6). Também Bonilla e Cepik $(2004,86)$ têm destacado que no "Espaço sub-regional os temas militares e políticos são objeto de uma securitização muito alta, devido ao caráter do conflito colombiano e sua evidente regionalização (...)".

\footnotetext{
3 Ao menos até 20I7, permaneciam 05 pendências territoriais sem solução na América do Sul (Bolívia -Chile; Colômbia-Venezuela; Guiana Inglesa - Venezuela; Uruguai-Brasil; ColômbiaParaguai).
}

140 Austral: Revista Brasileira de Estratégia e Relações Internacionais v.7, n.14, Jul./Dez. 2018 
Indo mais longe ainda que as perspectivas realistas, a produção institucionalista-Escola Inglesa como a de Kakowicz (I998), tem desenvolvido a tese do surgimento na América do Sul, como um todo, uma "zona de paz", e que especialmente o Cone Sul tem-se aproximado algo similar a uma comunidade pluralista de segurança, ou zona de paz, em que seus Estados-membros não tem já mais expectativas de resolver seus conflitos através do apelo à guerra. Na mesma direção, David Pion-Berlim (2000) tem argumentado que o processo de integração no Mercosul tem contribuído para gerar expectativas de resolução pacífica de conflitos intraestatais entre países membros daquela organização de integração. Uma perspectiva mais matizada dessa tese tem sido desenvolvida por Hirst, quem trabalhando a partir de conceitos da paz democrática e de comunidades pluralistas de segurança têm apontado para a conclusão de que, "Democratization is an important but insufficient condition to intensify cooperation in the Southern Cone [but] (...) In fact, thought security cooperation and democratization have not led to security integration they have been effective in diminishing previous mistrust and animosity among Southern Cone societies and states - especially between Argentina and Brazil" (Hirst 1998).

Dentro dessa mesma perspectiva liberal, os escassos conflitos inter-estatais na América Latina, também tem considerado a região latino-americana como um caso que apóia estudos em torno da teoria da paz democrática. Trabalho organizado por Dominguez tem reforçado os intensos vínculos entre a fortaleza das instituições democráticas no Cone Sul e o processo de paz e de segurança que a sub-região vive como produto da "paz democrática" (Dominguez I998). O próprio Dominguez, em trabalho com Shifter, ao introduzir a discussão sobre "pós-consolidação" e "desconsolidação", chama a atenção para a alta fragilidades e vulnerabilidades das democracias andinas (Dominguez e Shifter 2003).

No terreno empírico, esse tipo de argumento tem sido reforçado pela emergência no sistema interamericano de um regime institucional de cláusulas democráticas, e mesmo em algumas instituições de integração como o Mercosul. Também a perspectiva liberal de Domingues (2007) tem sustentado esse mesmo argumento ao enfatizar que arraigou-se fortemente no direito internacional dos países latino-americanos o princípio jurídico do iutis possidettis iuris, pelo qual os países da região concedem que os limites seus e os de seus vizinhos correspondem, em maior ou menor medida, àqueles da época da emancipação política as primeiras décadas do século XIX.

Argumentos construtivistas em pesquisas como as de Andrew Hurrel (I998) e Villa (2007) também têm apoiado a ideia da pouca propensão para o conflito dos países do Cone Sul no pós-Guerra Fria, apontando-se o 
Modernização Armamentista na América do Sul: Pressões Empíricas e Teóricas sobre as Visões Dualistas de Segurança Regional

surgimento, em ambos trabalhos, de uma comunidade frouxa de segurança, especialmente entre Argentina, Brasile, naquela sub-região sul-americana. Para Hurrel, um aspecto fundamental a considerar na construção dessa comunidade de segurança foi o processo de democratização em ambos países. O processo de redemocratização poderia ter fornecido para a Argentina e o Brasil uma visão comum de interesses e identidades e, sobretudo, fez com que compreendessem a vulnerabilidade e a fragilidade do processo de redemocratização e a importância de sua defesa conjunta. Assim, a cooperação bilateral passou a desempenhar um papel de escudo comum contra as ameaças domésticas ao processo de redemocratização. Embora essas ameaças fossem maiores na Argentina - onde o movimento militar dos Caras pintadas tentou quebrar a institucionalidade democrática no final da década de i980 -, o governo brasileiro percebeu que o amadurecimento da redemocratização no país dependia em muito da consolidação da democracia na vizinha Argentina. "Acreditar na redemocratização foi importante para redefinir os interesses, as identidades e um senso comum de propósitos" (Hurrel I998). Na mesma direção, Hurrel, tratando da variável "impacto da democracia" na política externa brasileira em relação à Argentina, credita à institucionalização de um sistema de normas sobre desarmamento e de confidence building entre Argentina e o Brasil o desmanche de fantasmas geopolíticos e o início de um ciclo de cooperação militar nos anos da democratização. Em conseqüência, criou-se um bem-sucedido conjunto de normas de autogovernança e de monitoramento de mecanismos recíprocos de $C B M s$ entre ambos os países, o que permitiu a estabilidade e a continuidade dos empreendimentos cooperativos. A institucionalização de acordos de cooperação militar tem incluído intercâmbios permanentes entre os staffs dos estados maiores militares dos dois países e a continuidade dos grupos de trabalho binacionais em matéria nuclear. Também as normas de confiança mútua entre ambos países abrangem a institucionalização dos canais de comunicação entre os dois presidentes, os altos funcionários (seguindo o caminho europeu do segundo pós-guerra Fria), consultas sobre a participação em missões de paz e o estabelecimento da cooperação na tríplice fronteira

\footnotetext{
4 Na definição de Karl Deustch (I957), ou de autores como Adler \& Barnett (I998), uma comunidade de segurança é um espaço geográfico transnacional, contíguo ou não, entre Estados e cujas sociedades têm expectativas de que os conflitos entre eles sejam resolvidos por meios pacíficos. O ponto chave de uma comunidade de segurança são os valores que a "comunidade" compartilha, sejam eles em sentido político, econômico ou cultural. Autores como Hurrel (I998) acreditam que no Cone Sul esteja surgindo uma comunidade de segurança que tem por base a redemocratização que se operou desde os anos 80 . E o próprio Deustch (I957) acredita que que há uma comunidade de segurança do Atlântico Norte que tem por base os valores e cultura liberal.
}

142 Austral: Revista Brasileira de Estratégia e Relações Internacionais v.7, n.14, Jul./Dez. 2018 
(Argentina-Brasil-Paraguai) para tratar aspectos de narcotráfico, contrabando e terrorismo (Villa 2007). No caso Brasil-Argentino, as ações conjuntas têm incluído também o desenvolvimento conjunto do veículo leve de combate "Gaúcho", para as Forças Armadas brasileiras e argentinas, que está na sua fase final de avaliação operacional nos dois países, antes do início da produção em série (Military Power Review 2008).

Uma tese intermediária é apresentada por Buzan \& Waever (2003). Estes autores têm sustentado a ideia de que na América do Sul existem dois subsistemas de segurança bem diferenciados: aquele dos países andinos (com ênfase no aspecto militar e em conflitos territoriais), e outro no Cone Sul, onde há a emergência de uma comunidade de segurança. Algumas situações de preferências diferenciadas entre os países sul-americanos às vezes parecem vir em apoio da dicotomia teórica de Buzan and Waever. Na Conferência Especial de Segurança da OEA, em 2003, "quando da solução adotada - a noção de segurança multidimensionals - [Sul-américa] mal conseguiu ocultar a distância conceitual entre, por exemplo, a ênfase do Brasil e da Argentina na pobreza como ameaça à segurança e as preocupações muito mais tradicionais do Equador e da Venezuela com ameaças militares estatais" (Cepik 2005). Essa mesma tese é sustentada por Mônica Hirst (2003) para quem os dois principais desenvolvimentos em segurança e defesa, no início do novo milênio, na América do Sul foram a diversificação de opções e prioridades de segurança e os padrões diferenciados de evolução militar no Cone Sul e na região andina.

Desta forma, a teoria de relações internacionais têm apontado em duas direções: ou América do Sul como uma zona de paz ou de parcial comunidade de segurança, ou América do Sul como uma região mista em que coexiste uma região mais atrelada a princípios tradicionais de segurança (a região andina) e outra de que vê a emergência de uma comunidade de segurança fraca. Em comum, ambas visões destacam a aversão sul-americana pela resolução violenta dos conflitos e o apego da região a princípios de direito internacional.

Mas que acontece quando alguns dos Estados da região sul-americana começaram a realizar um build-up armamentista pouco comum a esse sistema de segurança nas duas primeiras décadas desse século? Para encarar essa pergunta, que tensionará a tese da dualidade de sistemas de segurança e

5 A OEA institucionalizou o conceito de segurança multidimensional naquele ano. Por esse conceito, a organização assume que as fontes de ameaça aos Estados, governos e sociedades são plurais: eles podem ser militares, mas podem vir também da fome, da pobreza, dos desastres naturais, das mudanças climáticas, do terrorismo, do narcotráfico, do crime internacional, da corrupção nos Estados nacionais, de rivalidades étnicas e assim em diante. 
Modernização Armamentista na América do Sul: Pressões Empíricas e Teóricas sobre as Visões Dualistas de Segurança Regional

defesa na América do Sul, vamos proceder reconstruindo a seguir o build-up armamentista na América do Sul.

\section{Build-up Armamentista na América do Sul no Início do Milênio}

Embora não seja um argumento teórico, e sim de natureza empírico, o baixo investimento militar da América do Sul, tem sido aproveitado ou para mostrar a pouca preocupação da classe política com o rearmamento e modernização das forças armadas sul-americanas e latino-americanas em geral ou como argumento para mostrar que Sul-américa é uma região atípica ou excepcional, quanto que as capacidades militares ou a proximidade geográfica não são percebidas com tanta preocupação entre países vizinhos. Entre as regiões da chamada periferia do sistema internacional, o gasto percentual sul-americano anual é só superior à América Central (que tem o mais baixo gasto mundial) e a África. É importante perceber, no entanto, que o gasto sul-americano é bastante baixo quando comparado com outras regiões da periferia do sistema internacional, como Ásia e Oriente Médio. No entanto que os gastos militares regionais caíram entre I9I4 e I9ı6, e é

“I3 per cent lower compared with 2008, South American military spending grew by 4.I per cent to $\$ 57.0$ billion [between 20I6-20I7], the first annual rise since 2014 , bringing the increase since 2008 to I7 per cent... The rise in military expenditure in South America between 2016 and 2017 can mainly be attributed to the increases by Argentina (by I5 per cent to $\$ 5.7$ billion) and Brazil (by 6.3 per cent to $\$ 29.3$ billion). The increase in Brazil's military expenditure, the first annual increase since 20I4 and the largest since 2010, comes as a surprise given the country's current the largest since 20I0, comes as a surprise given the country's current economic and political turmoil. However, in 2017 the Brazilian Government loosened its budget deficit targets up to 2020 and released additional funds (\$4.I billion) for all major sectors, including the military. for all major sectors, including the military. Venezuela, amid a year of social and political unrest, increased its military spending in 2017 by I9 per cent compared with 2016 , since 20I3. However, the ongoing economic crisis in the country meant that for all major sectors, including the military. military spending in 2017 was still 75 percent lower than in 2008" (Nam 20I8, 4-5).

Um ponto concreto, olhando as tendências retrospectivamente nos gastos militares no médio prazo, os países latino-americanos com os maiores incrementos reais em despesas militares no período 2003-2007 pertencem

\section{Austral: Revista Brasileira de Estratégia e Relações Internacionais} v.7, n.14, Jul./Dez. 2018 
todos à região da América do Sul: Venezuela (com 78,53\%), Chile (com 53\%) e o Equador (com 49\%). Também na América do Sul se localizavam os três países com mais altos orçamentos militares: Brasil (que responde por $46 \%$ dos gastos, Colômbia (que responde por I5\%) e Chile (por I3\%) (Stalenheim et al. 2008, 200). Dos 44 bilhões de dólares que América Latina investiu em despesas militares em 2007, só os países da América do Sul gastaram US\$ 39,6 bilhões.

Desde 2005, o Chile e a Venezuela [e em menor grau o Brasil] foram os dois países que mais incrementaram a importação de armas em Sul-América, fazendo surgir a delicada questão de se a excessiva preocupação em modernizar as forças armadas por parte desses países poderia estar estimulando uma corrida armamentista na região. O Instituto Internacional de Estudos para a Paz de Estocolmo (Stockholm International Peace Research Institute, SIPRI) divulgou, em meados de 2008, o balanço do ano anterior, no que se refere à exportação, à importação e à transferência de armamentos ao redor do mundo. Na análise de médio prazo, o SIPRI constatou um aumento percentual das transferências de armamentos para a América do Sul: "Estados da América do Sul representaram 5\% do volume das transferências internacionais de armas convencionais importadas para o período de 2003-2007 - isto é, 47\% superior ao registrado em 1998-2002" (Holtom et al 2006).

$\mathrm{O}$ incremento coincide com o fato de que, entre 2004-2006, a região sul-americana teve uma série de três anos seguidos de forte crescimento econômico (cresceu a uma taxa média aproximada de 5,3\%)(CEPAL 2006), algo que não se registrava desde os anos $70 \mathrm{em}$ que o crescimento esteve próximo de taxas médias de 7,0\%. Embora o crescimento tenha recuado em 2007 para $4,9 \%$ na região sul-americana, algumas de suas economias mais fortes como Brasil, Argentina, Chile e a Venezuela respectivamente mantiveram o dinamismo no crescimento a taxas de $8,7 \%, 5,3 \%, 5,1 \%$ e $8,4 \%^{6}$, respectivamente. De outro lado, o crescimento econômico viu-se acompanhado por as melhora nos indicadores macroeconômicos principais em quase todos os países da região (inflação, ajuste fiscal e redução do débito público - e até uma boa entrada de capital externo que teve como impacto a desvalorização do dólar americano. Algumas fontes têm interpretado então o incremento dos gastos militares sul-americanos dos últimos cinco anos, como resultado do crescimento econômico, um dólar fraco, que estimula diferentes tipos de

6 Estado de São Paulo Online, "PIB da Argentina cresceu 8,7\% em 2007, diz Cristina Kirchner", I2 de fevereiro de 2008, available at http://www.estadao.com.br/economia/not_ecoi22970,0. htm, consultado em 27/08/2008; Dinheirama, "Alta do PIB, a Selic e o crescimento do Brasil", disponível em http://dinheirama.com/blog/2008/03/14/alta-do-pib-a-selic-e-o-crescimentodo-brasil/, acesso em 27/08/20I7. 
Modernização Armamentista na América do Sul: Pressões Empíricas e Teóricas sobre as Visões Dualistas de Segurança Regional

importação de bens, e a vontade política de modernizar as Forças Armadas da região, que em boa parte se confrontam com a obsolescência dos inventários em armamentos (IISS, 2008, 59).

Essas aquisições poderiam estar transformando América do Sul num mercado emergente para a venda de armas convencionais sofisticadas? Por exemplo, no caso do Chile, na análise de curto prazo, o país aparece como o principal importador sul-americano de armas da Grã-Bretanha, ocupando, em 2007, o segundo lugar nas exportações globais de armamentos da Grã-Bretanha para o mundo, empatado com a Romênia (para ambos países o Reino Unido exportou 9\%), só inferior aos I7\% que exportou ao mercado dos Estados Unidos. O dinamismo das importações de armamentos chilenos refletiu-se no fato de que o orçamento militar cresceu em 23\% em 2007 (Ibid 6o-6I). No caso da Venezuela, em 2007, o país foi o terceiro mercado das exportações de armamentos da Rússia para o mundo, com $5 \%$ do total das exportações russas, embora esse percentual é bastante inferior aos $45 \%$ que a Rússia exporta para China e os $22 \%$ que a Rússia exporta para o mercado da Índia (Ibid). "Não surpreendentemente países exportadores de armas Rússia em particular - têm apontado que com o sucesso econômico e o envelhecimento dos sistemas de armas os mercados latino-americanos oferecem boas oportunidades para a venda de novos equipamentos militares" (Ibid 59).

No sub-complexo de segurança andino, o caso que mais tem chamado a atenção, no entanto é o da Venezuela. Embora algumas fontes reconhecerem que, até 2006 , a Venezuela não era a principal investidora em armas na região sul-americana (Latin America Security \& Strategic Rewiev 2006, I-2), o fato é que a "Venezuela incrementou dramaticamente suas importações de armas, passando da posição 560 no período I998-2002 à posição 240 no período 2003-2007, como o maior importador regional" (SIPRI 2007). Só em 2007 , Venezuela incrementou seu orçamento em defesa em $78 \%$ (chegando a US\$ 887 milhões), transformando-se no maior gastador em termos reais na América do Sul naquele ano (Holtom et al 2008, 307). Apesar de que o montante em importações de armas seja menor que o do Chile para o período de 2003-2007 (U\$ I4I7 bilhões da Venezuela contra US\$2.283 bilhões do Chile), preços do petróleo em constante alta durante vários anos, a vontade política presidencial de melhorar as capacidades militares do país e a procura pela melhora na posição política regional venezuelana têm levado o país a incrementos cada vez maiores no orçamento militar Deve ser anotado que a Venezuela vem consolidando, ao longo dos anos, uma tendência que mostra a Rússia como o principal fornecedor de armamentos. Assim, no período de 2003-2007, a Rússia respondeu pelo fornecimento de 93\% do armamento comprado pela Venezuela, a China pelo 3\% e o Israel com 2\% (Ibid 306). 
Isso pode explicar porquê em 2006 e 2007 , a Venezuela ocupou a 8 a e a $4 \mathrm{a}$ posição entre os países em desenvolvimento que mais receberam entregas de armamentos e que mais assinaram acordos de transferência de armamentos (IISS 2008, 449). Os governos venezuelanos contam também com mecanismos legais que permitem que no ano fiscal sejam acrescentados fundos adicionais no orçamento militar. O principal mecanismo é a chamada Lei Paraguas (Lei Guarda-chuva), que possibilita ao governo negociar empréstimos externos para financiar gastos militares extras, nem sempre contemplados no orçamento militar original, embora o governo venezuelano tenha anunciado a intenção de usar com menos freqüência (e até eliminar) tal mecanismo (Ibid 2008).

Já no subsistema do Cone Sul, o Chile é o país que destaca-se nos esforços por adquirir armamentos de modernas tecnologias para recapitalizar suas forças armadas. No período de 2003-2007, o Chile transformou-se no maior importador de armas convencionais da região sul-americana. O país ocupava a posição 360 no ranking mundial de receptores de armamentos no período de 1998 a 2002, já no período 2003-2007 passou a ocupar a posição I2o (a primeira posição entre os países latino-americanos) (Holtom et al. 2008, 305). Também o Chile tem sido o único país latino-americano capaz de manter uma relação gastos militares/PIB em patamares superiores a $3.5 \%$ durante toda esta primeira década do século XXI, com exceção do ano 2007, em que foi superada em gastos reais pela Venezuela da região, aproximadamente U\$ 2, IOg bilhões.

Esse patamar constante de gastos foi possível por dois fatores: primeiro, porque o Chile teve um desempenho de sua economia bastante bom nos últimos anos. Por exemplo, entre 2004 e 2007 , o PIB chileno cresceu a uma taxa média anual de 6,2\%. Em segundo lugar, as forças armadas chilenas continuam se beneficiando da permanência da Lei do Cobre que data dos anos 50 do século passado7, e que modificada nos tempos do governo militar de Augusto Pinochet, pela qual Io\% das exportações do cobre são dirigidas a financiar despesas militares operacionais e compra de equipamentos ${ }^{8}$. E some-se a isso o fato de que o Chile é o principal exportador mundial de cobre e que os preços internacionais desse commodity tem tido um incremento bas-

\footnotetext{
7 Na verdade a Ley del Cobre (Lei do Cobre) data de I958, mas ela foi modificada em I998 ainda durante a ditadura de Augusto Pinochet.

8 Segundo um cálculo do The Economist o dinheiro alocado por conceito da "Ley del Cobre" já trouxe para o Chile 340 tanques da Alemanha, oito fragatas, dois novos submarinos e 28 aviões de combate F-I6. Ver The Economist, "South America defence: speak fraternally but carry a stick", 29/05/2008.
} 
Modernização Armamentista na América do Sul: Pressões Empíricas e Teóricas sobre as Visões Dualistas de Segurança Regional

tante alto nos últimos anos9. De acordo com cálculos, durante muitos anos a Lei do Cobre contribui com uma média anual de U\$200 milhões ao ano para o orçamento militar, mas devido ao incremento sem precedentes dos preços internacionais, a Lei seria responsável por financiar sozinha hoje em dia quase um US \$ bilhão, o que levou a fortes pressões por parte de setores políticos e sociais do Chile para revisar ou extinguir a lei.

Brasil é um caso de um estado transversal, ou de ponte, entre os dois subsistemas de segurança sul-americano. Embora como mostra o quadro I acima, Brasil não tenha tido, no meio prazo, o mesmo nível de gastos, em termos comparativos de PIB, que Venezuela e o Chile, no entanto, qualquer inclinação da região sul-americana em termos de gastos militares totais, ou em gasto em compra de armamentos, deve levar necessariamente em conta o Brasil, pela maior complexidade de sua economia, a metade do PIB da região (algo em torno de $56 \%$ ), e pela maior complexidade de suas metas políticas regionais e globais. Se bem que é verdade que, no caso do Brasil, no período de 2003 a 2007 , o país reduziu seu peso internacional como importador de armamentos convencionais, da posição 32 no período I998-2002 caiu para a posição 33. Esse decréscimo foi compensado pelo importante incremento do orçamento militar no ano de 2007 de mais de $33 \%$, de longe o mais importante numa década. Isso explica porque o Brasil da I $4^{a}$ posição entre os países com maiores gastos militares até 2006 , passou para a I $2^{\mathrm{a}}$ posição em 2007 (Stepanova 2008, I2).

\footnotetext{
9 O Chile é o maior produtor de cobre do mundo - com $25 \%$ da produção mundial - e até 2005 a indústria mineradora contribuirá com 6,I bilhões de dólares para o país, ou seja cerca de $25 \%$ do total das receitas fiscais previstas até 2005 , número que pode ser maior atualmente porque os preços internacionais do cobre, que estavam em média a US\$ I,7 a libra naquele ano, dobraram a partir de 2006 , e continuaram crescendo em 2007. Além disso o crescimento internacional dos preços do cobre teve um impacto significativo em economias de outros produtores sul-americanos, principalmente o Peru, e em menor medida Argentina e o Brasil. Para essas informações consultar: UniversiaKnowledge@Warten, "Preços do cobre aliviam cofres da América latina", 21/09/2005, http://wharton.universia.net/index. $\mathrm{cfm} ? \mathrm{fa}=$ viewArticle\&id=IO28\&language $=$ portuguese\&specialId $=$, consultado em $05 / 09 / 2008$ ; Último Segundo, "Com preço maior, roubo de cobre no Brasil cresce пा\% 2em 2007", 06/05/2008, http://ultimosegundo.ig.com.br/brasil/2008/05/06/com_preco_maior_roubo_ de_cobre_no_brasil_cresce_II_em_2007_I300233.html, consultado em 05/09/2008.
}

148 Austral: Revista Brasileira de Estratégia e Relações Internacionais v.7, n.14, Jul./Dez. 2018 


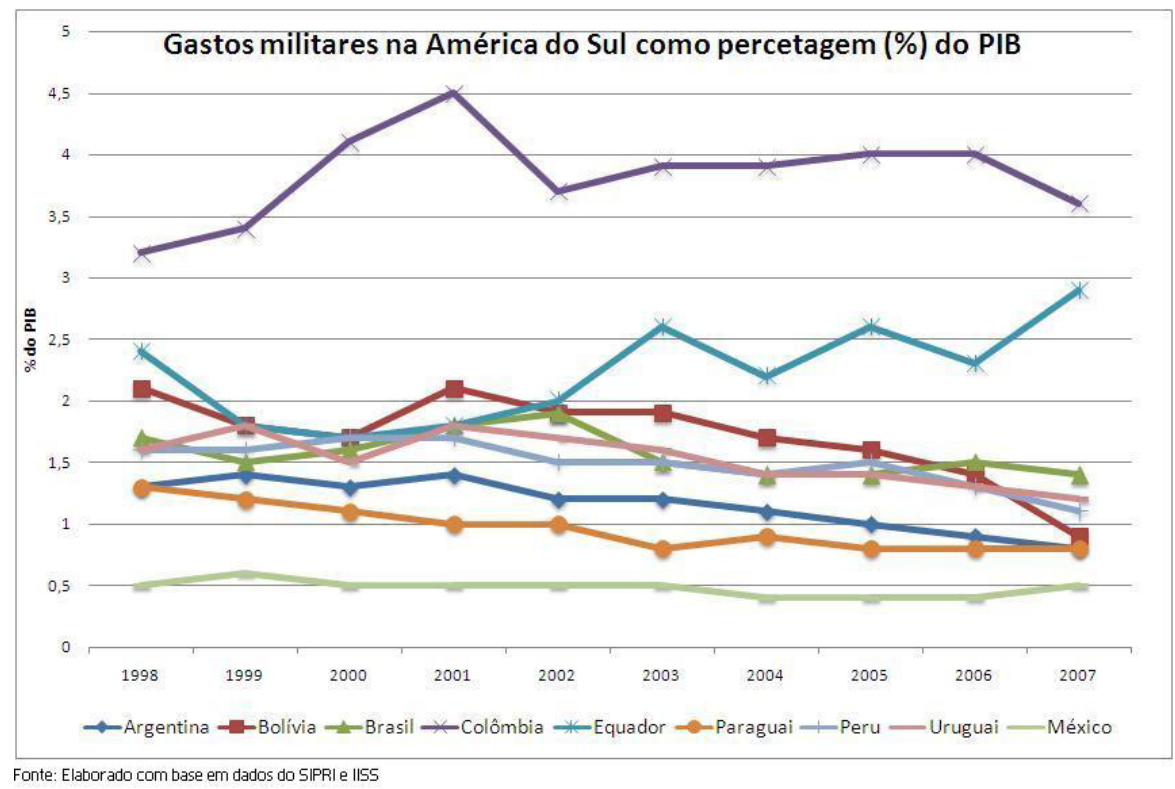

No entanto, devemos atentar para o fato de que os gastos militares brasileiros, de quase US $\$ 70$ bilhões no período 2003-20087, se diluem no tamanho da economia, cujo Produto Interno Bruto para o ano de 2007 chegou próximo de $R \$ 2,5$ trilhões (ou US\$ I,5 trilhão) (IBGE 2008). Disto resulta que, na relação gasto militar/PIB, o Brasil seja um país que gasta pouco quando comparado à Colômbia ou ao Chile, e só levemente maior que os casos de Argentina e Peru (ver, acima gráfico) No período de 2003-2007, o Brasil gastou uma omédia de I, $5 \%$ de seu PIB em despesas militares. No entanto, deve-se levar em conta que, apesar de o orçamento em defesa ter aumentado I5\% em média entre $2004-2007$ (e apesar dos 33\% de 2007), só $4 \%$ do orçamento está disponível para investimento em novas aquisições e upgrade de armamento. O resto da folha do orçamento militar é gasto basicamente em pagamento de pessoal, incluídas as despesas com aposentadorias e pensões militares. Dessa maneira, o gasto real de US\$ 8I8 milhões em compras e upgrade de armamento no período de 2003-2007 foi inferior aos do Chile e da Venezuela

O Brasil, no período de 2003-2007, importou a maior parte de seu armamento da União Européia (64\%), seguido dos Estados Unidos (17\%) e Canadá (7\%) (Holtom et al. 2008), e é possível que a importação destes e de outros países seja possível pelos planos de compras que têm, principalmente, a Marinha e a Aeronáutica. Algumas análises têm sugerido que o Brasil, assim como o Chile, tem dado preferência a fornecedores ocidentais, especial- 
Modernização Armamentista na América do Sul: Pressões Empíricas e Teóricas sobre as Visões Dualistas de Segurança Regional

mente pertencentes à OTAN, e não a outros, como a Rússia e a China, não por acaso, mas por uma racionalidade que envolve uma "escolha estratégica": na sua emergência, a potência regional sul-americana na próxima década, não parece prever uma relação de rivalidade com o Ocidente (Stratfor 2008), e sim, pelo contrário, uma relação de parceria para seus planos de desenvolver um papel importante na segurança regional. Tal evolução do gasto deve completar-se com a assinatura, em 2013, dos super-modernos caças suecos Gripen, dando início assim, concretamente, ao maior programa de modernização das forças armadas brasileiras.

\section{Tensões Empíricas e Conceituais nas que pressionam as Perspectivas Dualistas}

Como as análises tem reagido a esse incremento no build-up armamentista sul-americana? A verdade é que análises de cunho mais realista, sejam eles elaborados academicamente, ou de natureza conjuntural, têm recuperado fortemente, ao menos até 20 II, a ideia da vitalidade, e até de um certo dinamismo, de percepções de ameaças entre Estados vizinhos, sobretudo do Chile e da Venezuela. Assim, nos últimos anos, com alguma freqüência, tem-se escutado que América Latina, e especialmente América do Sul estariam entrando numa corrida armamentista. Freqüentes reportagens em meios da imprensa e declarações fortes de personalidades políticas têm alimentado esse temor ${ }^{\mathrm{I}}$. E também alguma produção acadêmica têm chegado à mesma conclusão; como sustentam análise de Malamud e Garcia: "A famosa corrida armamentista na América Latina, liderada pela Venezuela, não é mais só um discurso" (Malamud e Garcia 2006). No entanto, esse argumento não parece muito consistente: “(...) É duvidoso que eventos na região possam ser descritos exatamente como uma 'corrida armamentista' em termos clássicos. Aquisições tem sido primariamente motivadas pelos esforços em substituir ou atualizar (upgrade) capacidades militares com o objetivo de manter as capacidades existentes; responder às principais ameaças à segurança doméstica; reforçar vínculos com governos fornecedores; dinamizar a indústria militar doméstica; participar em missões de paz; ou melhorar o perfil internacional ou regional do país" (Holtom et al. 2008, 305).

Io Em finais de 2006, o presidente da Costa Rica, Oscar Arias, em reação às compra de armas por países como a Venezuela e o Chile afirmou que a região estava entrando numa "corrida armamentista. Ver para referências jornalísticas: Downie, Andrew, Time World, "A South American Arms Race?”. http://www.time.com/time/world/article/o,8599,1697776,o0. html; consultado em 23/07/20I7;

150 Austral: Revista Brasileira de Estratégia e Relações Internacionais v.7, n.14, Jul./Dez. 2018 
Um resultado desse tipo de análise é que há, em princípio, uma recuperação do estatal como ator forte de segurança; em segundo lugar, pressionam-se análises baseadas nos pressupostos conceituais das comunidades de segurança e da paz democrática, e mesmo até daquelas, que como as de Buzan e Wearver (2003), visualizam um sistema regional de segurança misto - metade tradicional, no subsistema dos países andinos, e comunidade de segurança no Cone Sul.

No entanto, a dramatização realista, de inícios deste século, sobre a corrida armamentista em Sul-América foi importante porque identificou e reconheceu certas dificuldades, imagens e desconfianças entre estados sul-americanos decorrentes do ciclo de upgrade e recapitalização do parque militar. E sobretudo porque, como um resultado conceitual, questiona o pressuposto dualista de subsistema andino (relações de segurança tradicional) versus subsistema Cone Sul (comunidade de segurança).

As perspectivas construtivistas e liberais vêm tensionada aquela perspectiva dual dado que nas condições políticas em que se dá o build-up: na primeira década deste século existia um grupo de países que procuram melhorar sua posição e perfil político regional e global, independentemente do sub-complexos regional em que se encontrassem, região Andina ou Cone Sul, especialmente Brasil e Venezuela, e, em menor medida, o Chile, e, nesse sentido, duas opções aparecem como mapas do caminho: modernizar suas capacidades militares de poder e reforçar vínculos e parcerias estratégicas com governos tidos como fornecedores globais de material militar avançado.

Nesse sentido, há uma condição de natureza política que alimenta o build-up armamentista do sistema regional de segurança sul-americano, que pouco tem a ver com preocupações estritamente tradicionais em si, leia-se militares. O sistema regional de segurança sul-americano vem atravessando por uma nova fase em que objetivos políticos e militares mais amplos deslocam preocupações tradicionais. Tais novos objetivos estão relacionados com a melhoria da posição política regional e até global de alguns países sul-americanos especialmente Brasil, o Chile e a da Venezuela. Certamente há motivações domésticas que também incentivam o build-up no caso desses três países. Contudo, tanto as metas domésticas de segurança que advém do build-up quanto as metas políticas regionais, por sua natureza latente não são explícitas, geram temores em vários países vizinhos àqueles três; posto que em presença do problema clássico de assimetria de informações, pobreza na comunicação, e ainda baixa institucionalização de medidas de confiança entre atores, propiciam-se condições para o ressurgimento de desconfianças, que alimentam falsas representações de fatos ou intenções (misrepresentation) de vizinhos em relação aos países que lideram o build-up. E, dado que os três 
Modernização Armamentista na América do Sul: Pressões Empíricas e Teóricas sobre as Visões Dualistas de Segurança Regional

atores estatais fonte dessas falsas representações localizam-se por todo a região sul-americana, questiona-se a fragmentação teórica dualista que vê um subsistema de segurança mais tradicional nos países andinos, e uma comunidade de segurança no Cone Sul.

Nessa lógica de metas regionais e globais no build-up militar chileno, objetivos e motivações regionais estão presentes. Uma motivação dos governos chilenos, assim como do alto comando militar, é a transformação do Chile numa potência regional militar capaz de atingir, em finais desta década, o que tecnicamente se conhece como "status militar OTAN" (ou "standard military NATO”) (Gonzales 2005), status este não alcançado por nenhum país sul-americano até nossos dias. Durante o período de 2003-2007, os principais mercados de importação de armamento convencional do Chile foram a União Europeia com 82\%, Estados Unidos com I5\% i e Israel com 3\% (Ibid). Essa escolha de países ocidentais como fornecedores, ou com fortes vínculos com o ocidente, poderia estar relacionado com o fato de que, com algumas análises sugerem, o Chile ter pretensões de adquirir aqueles status militar (Ibid).

Contudo, também a participação do Chile em missões de paz da ONU tem sido destacada como uma das principais motivações para a modernização das Forças Armadas e o investimento em compra de equipamentos militares. O Chile, que até I990 havia participado só de três missões de paz da ONU, aumentou em I5 missões a sua participação até os dias de hoje, e é o único país sul-americano a contar, desde I996, com uma "política nacional do Estado [chileno] para a participação em operações de paz" (Ramirez 2007).

Também no caso da Venezuela motivações estratégicas têm estado presente nas compras de armamentos: a melhoria da posição política regional da Venezuela. O governo venezuelano acredita na possibilidade da liderança da Venezuela na América do Sul. E uma maneira de aprimorar a posição política face a esse objetivo é a melhoria nas capacidades militares e a influência regional que daí advém. Na mesma direção, de melhorar suas capacidades militares para com isso melhorar sua posição política regional frente a competidores da envergadura do Brasil, também tem sido interpretado o reforço dos vínculos com a Rússia. Alguns analistas acreditam que se a aliança entre Venezuela e Rússia incomoda aos Estados Unidos, a modernização do arsenal venezuelano também desgosta o Brasil, não tanto pela ameaça militar em si, mas pela melhora política da posição venezuelana na tão especulada disputa pela liderança sul-americana entre ambos os países $^{\text {II }}$. Dessa forma, argumen-

II "Hugo Chavez achète de nouvelles armes en Russie", Le Figaro, 24/7/2008, http://www. lefigaro.fr/international/2008/07/24/0I003-20080724ARTFIGo0004-hugo-chavez-achetede-nouvelles-armesen-russie-.php, consultado em I3/8/2009; ver também, BBC-Brasil, 
ta-se que o Brasil, e também o Chile, estariam preparando uma estratégia para diminuir a influência que a Venezuela tem adquirido em relação a alguns países sul-americanos (Latin America Security \& Strategic Review, 2007) Nem o Brasil nem o Chile seriam indiferentes ao fato de que o governo venezuelano estaria tentando transformar a Venezuela numa potência regional dado que o país teria, no momento, capacidade de chegar a essa condição face às altas divisas derivadas da venda de petróleo ${ }^{\mathrm{I2}}$.

Por sua vez, os planos de modernização do Brasil das Forças Armadas brasileiras despertam, em alguns setores de países vizinhos, certos alertas sobre a possibilidade de o Brasil estar seguindo a mesma rota do Chile e da Venezuela (Gosman 2007). Como a maior parte dos países sul-americanos, uma razão alegada fortemente em favor da compra de novos armamentos é a defasagem tecnológica das Forças Armadas, especialmente da força aérea. Para colocar as Forças Armadas em dia, especialmente a Aeronáutica, aviões de combate super modernos do tipo Rafale francês precisam ser comprados.

Mas, na verdade, o projeto de modernização das Forças Armadas brasileiras ultrapassa as eventuais preocupações com a modernização das de qualquer país vizinho. A grande motivação brasileira está mais relacionada com uma projeção do papel do Brasil hemisférica e globalmente, isto é, a adequação do Brasil à sua condição de global political player emergente (ator político global emergente). Análises têm chamado a atenção para o fato de que embora as compras venezuelanas tenham recebido mais atenção (sobretudo pelo "fator Chávez), o Brasil é o único país sul-americano com capacidade de fazer um investimento de longo prazo. "O Brasil está melhor posicionado para iniciar um constante build-up armamentista apoiado pela sua própria indústria doméstica [...]. A escolha das três [companhias de aviação], significativamente dois de países da OTAN [EUA e França] e de um outro que poderia chegar a ser membro - sugere um ponto de essencial importância sobre a maneira como o Brasil visualiza seu futuro. Apesar das mutantes realidades geopolíticas no mundo, o Brasil na sua emergência a uma proeminência regional na próxima década, não parece prever maiores conflitos ou, ainda, uma relação de rivalidade com o Ocidente" (Stratfor 2008).

Talvez nesse contexto de motivações regionais e globais possa ser lida a elaboração do Plano Estratégico de Defesa Nacional. Em setembro de 2007

\footnotetext{
“Compra de armas da Venezuela causa 'inveja' ao Brasil”, 24/7/2008 , http://www.bbc.co.uk/ portuguese/reporterbbc/story/2008/07/080724_pressvenezuela_pu.shtml, consultado em I3/OI/2018.

I2 “Chávez busca 'armas e liderança' em Moscou”, BBC-Brasil, http://www.bbc.co.uk/ portuguese/reporterbbc/story/2008/07/080722_chavezmoscou_mp.shtml, consultado em I3/04/20I8.
} 
Modernização Armamentista na América do Sul: Pressões Empíricas e Teóricas sobre as Visões Dualistas de Segurança Regional

o presidente Lula, evitando referir-se a qualquer motivação que tivesse a ver com a Venezuela, ou qualquer outro país sul-americano, comunicou a criação de um grupo de trabalho, sob a direção do Ministério da Defesa e coordenado pelo intelectual Mangabeira Unger, para formular as diretrizes de um plano de modernização das Forças Armadas (Plano Estratégico de Defesa Nacional, ou Plano de Aceleração do Crescimento em Defesa - PAC em Defesa, como também tem sido chamado) que leva em conta três metas gerais e cinco objetivos concretos. Os primeiros referem-se a: I) a revisão das estratégias de defesa; 2) a reativação da indústria armamentista doméstica; 3) a autonomia da política de defesa. As preocupações concretas estão dirigidas a dar respostas às seguintes questões: I) quais as melhores estratégias para tempos de paz e guerra; organização das Forças Armadas, dotadas com a vanguarda tecnológica e operacional; 3) reativação da indústria armamentista nacional, direcionada à meta da autonomia em defesa; 4) identificação das Forças Armadas com a nação, especialmente quanto à defesa das fronteiras, em que a Amazônia aparece como uma prioridade, serviço militar compulsório e tarefas sociais; 5) estabelecimento de linhas para atuação das Forças Armadas em situações de manutenção da ordem e do estado de direito ${ }^{13}$.

O build-up armamentista na América do Sul, no entanto, tensiona também análises de middle-ground, como aquele baseado nos complexos regionais de segurança de Buzan and Waever (2003). O build-up armamentista sul-americano revela: I) tensões entre um movimento que puxa em direção a assets (neo) tradicionais de segurança, procura de metas políticas mais amplas através de meios militares [em casos como Brasil, Chile e a Venezuela], como exploramos na seção anterior, e outro que procura gerar certo capital social, através do desenho de confidence building measures (CBM). Contudo, tanto um quanto outro movimento não se esgotam no limite geográfico, como supõe a análise dos complexos regionais de segurança. Isto é, não é só a região andina que se comporta de maneira neo-tradicional, nem é só o Cone Sul em que as CBMs estão presentes. O que aqui temos chamado de comportamentos neo-tradicionais estão presentes em países andinos, como a Venezuela, e são acolhidos também como países do Cone Sul, como Brasil e o Chile. O mesmo podem dizer-se das CBMs, elas são contíguas, no sentido de que perpassam ambos espaços geográficos. Embora deva reconhecer-se que níveis de adoção e aplicação de CBMs são desiguais, tendo o Cone Sul uma participação mais forte naquelas que a região andina (Holtom 2008, 305).

O anterior pode ser ilustrado pelas reações que em setores do Peru e da Bolívia gera a modernização armamentista num típico problema da mis-

I3 Para todas estas indagações, ver "Lula launches preparations for superpower status", Latin America Security \& Strategic Review (2007)

154 Austral: Revista Brasileira de Estratégia e Relações Internacionais v.7, n.14, Jul./Dez. 2018 
representation a compra de modernos equipamentos militares por parte do Chile tem levantado hipóteses em setores políticos e acadêmicos peruanos e bolivianos de que a modernização das Forças Armadas chilenas teria como consequência imediata abrir uma brecha ampla na qualidade, sofisticação e tecnologia disponível do arsenal chileno em comparação aos primeiros. O gasto militar chileno também tem preocupado especialmente o Peru e a Bolívia, com os quais o Chile ainda tem litígios territoriais que datam de finais do século XIX e que são bastante sensíveis a todos eles. De acordo com estudo de Carlos Gutiérrez, "[...] as evidências que demonstram os gastos militares, e a aquisição de modernos sistemas de armas, por parte do Chile têm sido um fator determinante na visão que os vizinhos têm em relação a um tipo de corrida armamentista, que traria de volta os fantasmas dos conflitos históricos (Gutierrez 2007, 309). No entanto, é a escassez de intercâmbio de informação acurada que leva a esse tipo de imagem (temor). Mesmo até porque a possibilidade da modernização dos estoques chilenos serem utilizados para potenciais acertos de contas em contenciosos de fronteiras eventualmente criar ônus para o Chile, e outros países. Países fornecedores de armamentos podem se negar a vender por não estar claro para eles se suas vendas podem gerar condições para futuros conflitos regionais ou problemas mais estruturais, como o desequilíbrio militar regional. Em 2005, por exemplo, a Suíça cancelou a venda ao Chile de 93 modernos tanques Leopard II (depois comprados da Alemanha) e algumas fontes sugerem que a causa disso foi a desconfiança do governo da Suíça sobre a real motivação chilena para tais compras $^{\mathrm{I} 4}$.

No caso do Chile e o Peru, que disputam desde finais do século XIX áreas marítimas, como sustenta um trabalho de Farih Kahhat, embora os avanços na cooperação persista entre ambos países, uma certa desconfiança que é alimentada em documentos oficiais reservados em que se projetam hipóteses de conflito (não oficiais) baseados em informação imprecisa ou argumentos incoerentes (Kahhat 2006).

No entanto, tem havido, por parte do Chile, um esforço para melhorar a qualidade da informação através da construção de regimes de segurança (CBMs) com seus vizinhos peruanos e bolivianos das preocupações que o incremento das compras de armamentos têm levantado naqueles. Sobretudo depois da aquisição chilena dos aviões de combate F-16 (Higuera 2005), em inícios desta década, as tensões derivadas desse fato foram aliviadas pelo início de acordos geradores confiança. Na época dos governos de Ricardo Lagos, no Chile, e Alejandro Toledo, no Peru, as tensões e desconfianças aumenta-

I4 "Chile teme que conflicto con Perú afecte compra de armas", 22/II/2005, http://www. gatoencerrado.net/store/noticias/35/35249/detalle.htm, consultado em 22/9/20I7. 
Modernização Armamentista na América do Sul: Pressões Empíricas e Teóricas sobre as Visões Dualistas de Segurança Regional

ram fortemente, mas foram atenuadas a partir do início do segundo governo do presidente peruano Allan Garcia. As medidas de CBMs entre Chile e Peru têm incluído reuniões entre os ministros da Defesa, tentando reativar um mecanismo chamado de Encontro 2+2, que é uma comissão permanente de consulta, coordenação política e intercâmbio de informações, da qual participam os ministérios da Defesa e das Relações Exteriores de ambos os países, e cujas atividades haviam sido suspensas desde a época do governo de Alejandro Toledo (Latin America Security \& Strategic Review 2007, 9) .

No caso das relações Chile-Bolívia, que tiveram as mesmas congeladas por vários anos ainda nesta década, e apesar de declarações bilaterais tensas no início do governo de Evo Morales, as relações a partir do ano de 2007 melhoraram muito e têm gerado uma série de CBMs anunciada pelos governos de ambos os países e que têm incluído: destruição de minas terrestres que o Chile disseminou nos anos da ditadura de Pinochet ao longo da fronteira com a Bolívia, assim como o envio ao Chile de soldados bolivianos para serem treinados em: I) atividades antiminas; 2) intercâmbio de estudantes bolivianos em academias militares chilenas; 3) mecanismos de consulta permanente e esforços de cooperação antidrogas (Ibid, 9).

Em ambos espaços geográficos sul-americanos, atenua as possibilidades de uma corrida armamentista o fato de que medidas formais e informais de geração de confiança (Confidence-Building Measures, CBMs) têm desempenhado um importante papel em diminuir o impacto da aquisição de armas na América do Sul (Holtom et al. 2008 304-305) ou de atenuar aprofundamentos de conflitos derivados de litígios de fronteiras ainda não resolvidos. As CBMs objetivam criar transparência, mecanismos de monitoramento nos procedimentos e nas operações militares, diminuir as assimetrias de informações entre os Estados-membros de um regime de normas no tratamento de problemas de segurança e desarmamento ${ }^{15}$. Se as compras de armamentos sugerem um movimento para padrões (neo) tradicionais de segurança no sistema sul-americano posto que dinamizam eventuais e históricos de "inimizade", de outro lado, esse movimento é problematizado, ou de alguma maneira atenuado, por padrões de "amizade baseado na procura de CBMs, que geram condições para o alongamento da comunidade de segurança fraca, (ou loosely coupled security community, no sentido descrito por alguns teóricos (Adler e Barnet I998) da comunidade de segurança, especificamente nos países do Cone Sul como a Argentina e o Brasil (Oelsner 2009).

I5 Ao respeito de CBMs na América Latina consulte-se o excelente trabalho de Bromley, M. \& Perdomo (2005), C. "CBMs in Latin America and the effect of the arms adquisition by Venezuela”, Working Paper 41/2005. Available at http://www.realinstitutoelcano.org/ documentos/2I6.asp, acessado em 05/09/2008.

156 Austral: Revista Brasileira de Estratégia e Relações Internacionais v.7, n.14, Jul./Dez. 2018 


\section{Conclusões}

Retornado o argumento teórico as análises aqui temos chamado de duais têm sustentado que na América do Sul existem dois subsistemas de segurança diferenciados: o dos países andinos (com ênfase no aspecto militar e em conflitos territoriais), e outro no Cone Sul, onde há a emergência de uma

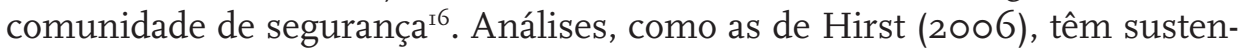
tado que os dois principais desenvolvimentos em segurança e defesa no início do novo milênio na América do Sul foram a diversificação de opções e prioridades de segurança e os padrões diferenciados de evolução militar no Cone Sul e na região andina. De outro lado, análises baseadas em conceitos de comunidade de segurança e de paz democrática têm frisado o desenvolvimento no Cone Sul de comunidades de valores e o impacto da natureza democrática de seus sistemas políticos na consolidação de relações cooperativas. Contudo, os gastos militares sul-americanos do quinquênio 2003-2007 mostram que não há dois complexos no sentido estrito. As metas regionais e globais de países como Brasil, Chile e a Venezuela, que são metas mais de natureza política que militar propriamente dito, contudo, sofrem do problema de misrepresentation, dado que não é claro para alguns dos Estados vizinhos àqueles três países quais são as motivações por trás do build-up destes. Assim, o que para Brasil, Chile e Venezuela poderiam parecer metas políticas são interpretadas como metas tradicionais por vizinhos, ou mesmo entre eles, como no caso Brasil-Venezuela. Isto é, com reflexo em eventos, a misrepresentation é comum ao complexo sul-americano, e não localizadas no subcomplexo andino, ou no mínimo a polos estatais de irradiação das desconfianças sobre as motivações envolve países de ambos subsistemas.

Embora seja correto que Sul-américa tenha construído uma histórica zona de paz se por isso deve entender-se a ausência de guerras, ou poucas guerras desde a formação do moderno sistema de Estados sul-americanos, também é verdade que as análises dualistas tem prestado pouca atenção para

I6 Na definição de Karl Deustch (I957), ou de autores como Adler \& Barnett (I998), uma comunidade de segurança é um espaço geográfico transnacional, contíguo ou não, entre Estados e cujas sociedades têm expectativas de que os conflitos entre eles sejam resolvidos por meios pacíficos. O ponto chave de uma comunidade de segurança são os valores que a "comunidade" compartilha, sejam eles em sentido político, econômico ou cultural. Autores como Hurrel (I998) acreditam que no Cone Sul esteja surgindo uma comunidade de segurança que tem por base a redemocratização que se operou desde os anos 80 . E o próprio Deustch (I957) acredita que que há uma comunidade de segurança do Atlântico Norte que tem por base os valores e cultura liberal. 
Modernização Armamentista na América do Sul: Pressões Empíricas e Teóricas sobre as Visões Dualistas de Segurança Regional

o problemas derivados de escassez de informação no processo do build-up sul-americano, o que tem por conseqüência o incremento de temores sobre intenções, capacidades e ações projetadas sobre atores estatais. De alguma maneira isso chama a atenção para a precariedade de Confidence-Building Measures (CBMs), principal ferramenta dos regimes de segurança na América Sul, através dos quais é possível aproveitar "acurada informação para acalmar falsos boatos" (Lindle, 2007 , p. I) e que permitem conhecimento recíproco dos atores, e de seus intenções entre si. As CBMs têm desempenhado um importante papel em atenuar o impacto da aquisição de armas na América do Sul (Holtom et al. 2008, 304-305) ou de atenuar aprofundamentos de conflitos derivados de litígios de fronteiras ainda não resolvidos.

Alguns trabalhos teóricos, como vimos, têm tentado explorar a existência de dois subsistemas de segurança na América do Sul, um na região andina, em que se sustenta a competição militar tradicional, e outro no Cone Sul, em que estaria emergindo uma comunidade de segurança.

Mais que uma corrida armamentista todos quase os países sul-americanos iniciaram em inícios do milênio uma recapitalização de seu obsoleto estoque militar, que data a maior parte dele dos anos 50 e 60, e o mais moderno dos anos 80 . Essa recapitalização significa exatamente uma atualização (upgrade) e substituição de equipamentos militares (Hodge, 2008). Porém, há muita assimetria na recapitalização. Chile e a Venezuela tem-se visto beneficiado por duas condições. Primeiro, porque há uma tendência forte em ambos países em utilizar suas commodities de exportação (petróleo e cobre) para financiar gastos militares e apoiar seus planos de modernização das Forças Armadas; segundo, ambos países valem-se de mecanismos extra-orçamento original em defesa (Ley del Cobre no Chile; Lei Paraguas em Venezuela) para financiar os gastos militares, de tal maneira que o orçamento militar original de cada ano fiscal raramente coincide com o gasto militar real. O fim das crises econômicos que assolaram América Latina entre os anos de 1997 a 2000 também propiciou condições financeiras para a reemergência de projetos da modernização das forças armadas (Martin 2006, 3). De tal maneira, a re-capitalização, sob a forma de upgrade ou novas compras, independentemente das motivações reais ou latentes, é passível de ser considerado um sinal de retomada e normalização de relações entre civis e militares na América do Sul. No caso do Brasil, a compra dos caças Gripen constitui o ponto mais alto daquela recapitalização e modernização armamentista.

Embora eventuais pressões existem, derivadas da correlação que alguns países vizinhos a Chile e a Venezuela, podem fazer entre modernização de armamentos e contenciosos fronteiriços ou rivalidades históricas, fundamentalmente, o build-up tanto de países com maior investimento na região 
andina ou no Cone Sul, procura melhorar a posição e perfil político regional, especialmente Brasil, que tem objetivos mais globais dentre dos países sul-americanos, e a Venezuela, com seu empenho em construir um espaço para sua liderança regional. Nesse sentido, dois caminhos aparecem como fundamentais para atingir tais metas: modernizar suas capacidades militares e reforçar vínculos e parcerias estratégicas com governos tidos como fornecedores globais de material militar avançado. Mesmo assim não há uma relação necessária entre objetivos políticos e condições militares. O caso do Chile ilustra bem esse aspecto: mesmo uma acelerada modernização de suas Forças Armadas, que tem incluído fortes compras de armamentos sofisticados, seus objetivos políticos com vistas à liderança regional são bastante limitados e discretos.

Porém, uma consequência teórica singular do build-up armamentista sul-americano é que pressiona também contribuições conceituais que separam os dois subsistemas sul-americanos, retomando, um mais tradicional e próximo de comportamentos realistas na região andina, e um mais próximo de uma comunidade se segurança entre países do Cone Sul. Como a maior parte dessas análises duais se baseiam numa relação entre a natureza do sistema político (o impacto da redemocratização doméstica sobretudo, o que é bastante claro no caso das análises liberais e construtivistas) e um tipo de relação de segurança cooperativa que tende a derivar da natureza democrática do sistema, leva não só a uma securitização das relações no subcomplexo regional andino, como tendem esvaziar da agenda de deliberação dos estados andinos, o item democrático como ferramenta de segurança e de política externa. A verdade é que fracionando o sistema sul-americano aquele tipo de análise não percebe que o debate sobre esse item está em todo o sistema sul-americano "For these reasons the changes that occurred beginning in the late I980 and that have continued into the 2Ist century are truly remarkable. In a little more than a decade, democracy has gone from being an internal matter of states to a subject of intense deliberation in regional forums" (Arceaneaux and Pion-Berlin 2005, 87).

Na verdade, se atentarmos para o build-up armamentista sul-americano contemporâneo, há características em comum a ambos espaços geográficos, que em vez de lhes fragmentar teoricamente acabam lhes atribuindo uma certa contigüidade. Ambos espaços tem atores preocupados com metas militares, embora essas metas não tenham fortes objetivos tradicionais; em ambos espaços, há atores estatais que mais tem aprofundado na modernização de suas Forças Armadas - Chile e a Venezuela -, no entanto, levantam, eventualmente, preocupações entre vizinhos, devido a percepções de ameaças que remontam ao passado; ambos subsistemas de segurança tem desenvolvi- 
Modernização Armamentista na América do Sul: Pressões Empíricas e Teóricas sobre as Visões Dualistas de Segurança Regional

do CBMs com seus vizinhos, embora, possa ser frisado, que estas são mais consistentes no Cone Sul que na região andina. A diferença entre os subsistemas de segurança sul-americanos parece dar-se mais pelo lado da estabilidade política de que pelo aspectos de segurança regional. Certamente o subsistema andino, desde os anos 9o, apresenta um grau de instabilidade política maior que os sistemas políticos do Sul

\section{REFERÊNCIAS}

Adler, Emanuel and Michael Barnett, eds. 1988. Security Communities. Cambridge: Cambridge University Press.

Arceaneaux, Craig and David Pion-Berlin. 2005. Transforming Latin América: the international and domestic origins of change. Pittsburg: University of Pittsburg Press.

Bonilla, Adrián and Marcos Cepik. 2004. "Seguridad andino-brasilena: conceptos, actores y denates". In Agenda de seguridad andino-brasilena, organized by Marcos Cepik and Socorro Ramírez. Bogota: Fundación Friedrich Ebert/UFRGS/IEPRI.

Bromley, M. e C. Perdomo. 2005. "CBMs in Latin America and the effect of the arms acquisition by Venezuela", Working Paper. Accessed September 5, 2008. http://www.realinstitutoelcano.org/documentos/2i6.asp .

Buzan, Buzan. And Ole Waever. 2003. Regions and Power. The Structure of International Security. Cambridge: Cambridge University Press.

Comissão Econômica para a América Latina e o Caribe (CEPAL). División de Desarrollo Económico. 2006. "Estudio Económico de América Latina e Caribe". Accessed June 8, 2018. https://repositorio.cepal.org/ bitstream/handle/I1362/I063/I/So60040I_es.pdf

Deutsch, Karl. 1957. Political Community and the North Atlantic Area: International Organization in the Light of Historical Experience. Princeton: Princeton University Press.

Diamint. Ruth. 200I. Democracia y seguridad en América Latina. Buenos Aires: Grupo Editor Latinoamericano.

Dominguez, Jorge. 2007. International Cooperation in Latin America: The Design of Regional Institutions by Slow Accretion. In Crafting Cooperation: Regional International Institutions in Comparative Perspective, edited by A. Amitav and I. J. Alastair. New York: Cambridge University Press. 
Dominguez, Jorge and Michael Shifter. 2003. Constructing democratic governance in Latin América. Baltimore: John Hopkings University.

Dominguez, Jorge, ed. 1998. Seguridad internacional, paz y democracia em el Cono Sur, paz y seguridad en las Américas. Santiago de Chile: Woodrow Wilson Center, FLACSO (Chile), Inter-american Dialogue.

Gonzalez Cabera, P. 2005. "Chilean military plans to be military-standard for NATO for 20I0", El Mercurio, I8 de julho.

Gosman, Eleonora, "Brasil duplica el gasto militar para recuperar su poder regional", Clarin, 30/10/2007. Acesso em 22 de janeiro de 2018. http://www.defesanet.com.br/alt/br.htm.

Gutiérrez, Carlos. 2007. "Chile, Perú y Bolivia: entre el conflicto y la cooperación”. In Seguridad humana y nuevas políticas de defensa en Iberoamérica, edited by Isidro Sepúlveda. Madrid: Instituto Universitario General Gutiérrez Mellado.

Higuera, J. "Chile confirms plans to buy second-hand Fi6s", Janes's Defense Weekly, 6 de julho de 2005 .

Hirst, Mônica. 2006. "La fragmentada agenda de (in) seguridad regional". In Seguridad $y$ Democracia. Buenos Aires: Fundación Friedrich Ebert-Instituto Latinoamericano de Investigaciones Sociais (FES;ILDDIS).

I998. "Security policies, democratization and the regional integration in the Southern Cone". In International security \& democracy: Latin America and the Caribbean in the post-cold war era, edited by Jorge I. Dominguez, Jorge. Pittsburgh: Pittsburgh University Press.

Hodge, Natham. 2008. "FIDAE highlights continuing upsurge in Latin American procurement”, Jane's Defence Weekly, April o3.

Holtom, P; M. Bromley and D. Wizeman. 2008. "International arms tranference”. In SIPRI Yearbook 2008. Armament, disarmament and international security. Oxford: Oxford University Press.

Hurrel, Andrew. I998. "An emerging security community: in South America?. In Security Communities, edited by Emannuel Adler and Michael Barnett. Cambridge: Cambridge University Press.

IBGE (Instituto Brasileiro de Geografia e Estatísticas). "Brasil em sínteses". Acesso em 20 de abril de 20I8. http://www.ibge.gov.br/brasil_em_ sintese/default.htm

Kacowicz, Arie M. 1998. Zones of Peace in the Third World: South America and West Africa in Comparative Perspective. State Universitity of New York Press.

2005. The impact of norms in international society: the Latin Amer- 
Modernização Armamentista na América do Sul: Pressões Empíricas e Teóricas sobre as Visões Dualistas de Segurança Regional

ica experience, 1881-2001. Notre Dame (Indiana): University of Notre Dame Press.

Kahhat, Farid. 2006. "Las relaciones entre Chile y Perú en el ámbito de la seguridad: entre la cooperación y la desconfianza". Fuerzas Armadas y Sociedad, 20 (I): 3-16.

Latin America Security \& Strategic Review. 2007. "Brazil and Chile lead strategies to contain Chavez without isolate him". Latin America Security Q. Strategic Review, setembro: I-2.

. 2006. "Venezuela buys more arms from Russia - but is not the region's biggest spender". August.

. 2007. "Thawing relations with Peru", Latin America Security Q Strategic Review, setembro.

Lindle, Dan. 2007. Promoting peace with information: transparency as tool of the security regimes. Princeton: Princeton University Press.

Martin, F. E. 2006. "The Latin America military in the new millenium". Hemisphere, $\mathrm{I} 6$.

Military Power Review. "Ranking do Poder Militar na América do Sul". Acesso em 28/II/20I7. http://www.militarypower.com.br/ranking.htm.

Oelsner, Andrea. 2009. International Relations in Latin America: Peace and Security in the Southern Cone. Publisher: Routledge.

Pion-Berlin, David. 2000. "Will soldiers follow? Economic integration and regional security in the Southern Cone. Latin American Politics and Society 42 (I): 43-69.

Pion-Berlin, David and Harold Trinkunas. 2007. "Attention Deficits: Why Politicians Ignore Defense Policy in Latin America". Latin American Research Review 42 (3): 76-IoO.

SIPRI Arms Transfers. 2007. "SIPRI data shows drop in international arms deliveries, orders remain high". Acesso em 20 de março de 2018. http://www.sipri.org/contents/armstrad/PR_AT_data_2007.html.

Ramírez, Juan M. 2007. "Comentarios sobre el proyecto que modifica la Ley nffl I9.067 y establece normas para la participación de tropas chilenas en operaciones de paz". Centro Estratégico de Estudios - CEE. Chile, I-8.

Stepanova, Ekaterina. 2008. “Trends in armed conflicts”. In SIPRI Yearbook (Summary). Acesso em: 20 de fevereiro de 20I8. https://www.sipri. org/yearbook/

Stalenheim, C., C. Perdomo, and E. Skons. 2008. "Military Expenditure”. In SIPRI Yearbook 2008. Armament, dissarmament and international 
security. Oxford: Oxford University Press.

Stratfor. 2008. Brazil: Momentum builds for Defence Reform", 2 de outubro. Acesso em 05 de março de 20I8. http://www.stratfor.com/analysis.

The International Institute for Strategic Studies (IISS). 2008. "Caribbean and Latin América - Defence and economics”, in: Military Balance-2008, London: Routledge, 2008.

Tian et al. SIPRI. 20I8. "Trends in world military expenditure, 20I7”. SIPRI. Sheep fact (May 20I8). Acesso em 26 de mayo de 2018. https:// www.sipri.org/publications/2018/sipri-fact-sheets/trends-world-military-expenditure-20I7; acesso em: 22 de maio de 20I8. https://www. sipri.org/sites/default/files/2018sipri_fs_I805_milex_2017-04/.pdf.

Villa, Rafael Duarte. 2007. "Brazilian foreign affairs: social capital and the democratic discourse in South America". Revista Brasileira Ciências Sociais 3, special edition. Acesso em 20 de maio de 2018 . http://socialsciences.scielo.org/pdf/s_rbcsoc/v3nse/scs_ao4.pdf.

\section{RESUMO}

A pesquisa que foca em sistemas de segurança na América do Sul costuma identificar a existência de dois subsistemas regional de segurança: um nos países andinos do Norte, de características mais tradicionais, com tensões militarizadas nas fronteiras e intensos problema de narcotráfico, e um segundo localizado no Cone sul, com regimes de segurança e integração, que teria condições de ser uma comunidade de segurança. A isso chamamos de visão dualista de segurança. Este artigo tenciona essa tese ao mostrar: primeiro, que desenvolvimentos contemporâneos, e preocupações, com a compra de armamento sofisticados, por parte de alguns países sul-americanos, especialmente o Chile a Venezuela e o Brasil nas duas primeiras décadas deste século é um ponto crítico que tenciona a ideia de uma zona permanente de paz (democrática) localizada unicamente no Cone Sul. Na verdade, compras de armamentos transformam a região da América do Sul num único complexo regional de segurança com tensões e representações militarizadas tanto no sistema andino como no Cone Sul.

\section{PALAVRAS-CHAVE}

Visão Dualista; Armamentos; América do Sul; Segurança. 